\title{
What is causing the 'long-hauler' phenomenon after COVID-19?
}

COVID-I9 HAS BEEN WITH us for more than 1 year (our annus horribilis), and many patients suffer long-term consequences. The term for this in the United Kingdom and Italy is long COVID; in Spain it is Covid persistente, and in Germany it is mit Corona leben (living with coronavirus). In the United States, it is commonly referred to as "long-hauler" COVID-19.

See related article, page 267

"Brain fog," tremors, limb stiffness, confusion, and signs and symptoms involving cognitive functions are becoming apparent in long-hauler patients with multiorgan complaints. ${ }^{1}$ The frequency and severity of these features and of psychiatric findings are becoming clear. ${ }^{2}$ Some speculate that COVID-19 may exacerbate underlying neurodegenerative syndromes such as Alzheimer disease, Parkinson disease, and multiple sclerosis. ${ }^{3}$

A study in London identified the following risk factors for long COVID ${ }^{4}$ :

- Age (particularly > 50)

- Sex (women are less likely to develop severe COVID-19 but more likely to develop long-hauler COVID-19)

- Reporting more than 5 symptoms (ie, more than cough, fatigue, headache, diarrhea, loss of sense of smell) in the first week of infection

- Excess weight

- Asthma.

More risk factors are sure to be reported. ${ }^{5}$

doi:10.3949/ccjm.88a.21009

\section{LONG-TERM NEUROLOGIC SEQUELAE OF OTHER INFECTIONS}

There is a long history of patients describing chronic nonspecific symptoms after infection.

"Russian influenza," so named because it apparently began in St. Petersburg in November 1889 , is perhaps the first such example. This postinfluenza affliction, also called grippe catalepsy, postgrippal numbness, psychosis, prostration, and inertia, affected many of the leaders of the United Kingdom, including the prime minister. It kept coming back for over a decade, with an initial epidemic in 1893, and subsequent flares in 1893, 1895, 1898, and 1899-1900. ${ }^{6}$

Epstein-Barr virus infection is another infectious disease with varied long-term consequences. Some patients are ill for only a few weeks, while others experience debility that seems to know no end.

Lyme disease, due to infection with Borrelia burgdorferi, causes well-known clinical manifestations and responds to antibioticsin most patients. A small proportion, however, report fatigue, brain fog, cognitive dysfunction, hallucinations, weakness, tachycardia, numbness, tingling, shortness of breath, "rolling waves of symptoms," and other nonspecific symptoms that seem interminable. Given that there may be up to 476,000 new cases of Lyme disease per year in the United States, ${ }^{7}$ even a small proportion is a large number.

Local outbreaks in which previously healthy people experience chronic and unrelenting nonspecific complaints after infections with B burgdorferi, Epstein-Barr virus, or other pathogens have been ascribed, without definitive evidence, to persisting infection. Controversies about the cause may relate directly to
We are still

early in our understanding of COVID-19 and the full spectrum of its manifestations 
this lack of definitive evidence, with patients and practitioners compelled to find a reason for this suffering. All too often, families and clinicians dismiss or minimize these chronic symptoms; and all too often, misguided therapies can lead to toxicity, frustration, and despair.

Similarly, for many years, researchers have sought evidence of prior infection as the cause of myalgic encephalopathy/chronic fatigue syndrome. And many patients with fibromyalgia recount a prior viral illness.

An explanation for the persistence of nonspecific complaints, which often begin after an infectious illness, is that these symptoms are related to stress or anxiety, or both. In the current era, this theory was probably aided, if not initiated, by social media. Although postpolio syndrome, chronic brucellosis, epidemic neurasthenia, and epidemic myalgic encephalomyelitis were described long ago, more recent outbreaks have occurred at a time when respect for and trust in medical authority have waned, and many people place their trust in social media, a source of much that is inaccurate, unproven, and often harmful. If the media can stoke anger and resentment to the point of initiating insurrection, they can certainly stir stress, fatigue, and achiness into syndromic pots to serve many others.

Some have explained or dismissed these chronic complaints as being the result of "affective disorders," a verdict that essentially precludes any further medical investigation as to etiology and mechanism of persistence. ${ }^{8}$

\section{HOW DOES INFECTION DAMAGE THE CENTRAL NERVOUS SYSTEM?}

How can an infection cause brain dysfunction, with long-term symptoms?

SARS-CoV-2 invades the host cell by first binding to angiotensin-converting enzyme 2 (ACE2) on the cell membrane. Entry activates Toll-like receptors 3, 7, and 8; viral RNA sensors in the endosome; and cytosolic receptors, including retinoic acid-inducible gene I, melanoma differentiation-associated gene 5, and nucleotidyl-transferase cyclic guanosine monophosphate-adenosine monophosphate synthase, which then induce secretion of interferons and other inflammatory cytokines. ${ }^{9}$

Then what happens?

\section{LOCAL INFECTION}

Local inflammation related to the immune response to the organism can be indiscriminate, both killing the organism and damaging cells of the nervous system: neurons, endothelial cells, or glial cells (from the Latin for "glue") including oligodendrocytes, microglia, and astrocytes. Invasion of the brain by SARS$\mathrm{CoV}-2$ has been established. ${ }^{10}$

Loss of sense of smell, which is common in COVID-19 and occasionally its only clinically apparent feature, ${ }^{11}$ may be due to local infection. The olfactory nerve may be an avenue of entry for the virus. SARS-CoV-2 appears to infect the olfactory ciliated cells of the nasal epithelium, causing deciliation ${ }^{12}$ with subsequent loss of function.

Normal olfaction does not always return; some patients are left with a perverted sense of smell-eg, coffee smells like barbecue. Possibly, in the process of healing in the nasal epithelium, the rewiring goes awry. This problem is sufficiently common and intrusive that it was the subject of an article in the New York Times Magazine. ${ }^{13}$

Other parts of the brain may also be susceptible to infection with SARS-CoV-2, although this is not yet proven. Postmortem studies have found that the ACE2 receptor is expressed broadly in blood vessels of a variety of sizes in the frontal cortex; ACE2 expression was upregulated in patients with hypertension and dementia.

In vitro, the virus did not kill primary human brain microvascular endothelial cells, but its spike protein altered the integrity of the human blood-brain barrier. ${ }^{14}$ The spike proteins may trigger inflammatory changes in brain endothelium that alter blood-brain barrier function. ${ }^{15,16}$ Subsequent passage of serum inflammatory proteins across the compromised blood-brain barrier may cause damage to the brain.

Inflammatory cells are also found in the brain in this setting. ${ }^{17}$ Some of these inflammatory cells may actually be carrying the virus, a phenomenon known as a "Trojan horse," with infected macrophages spreading the infection. ${ }^{18}$ This phenomenon was previously noted in the spread of human immunodeficiency virus.

In the lungs, viral entry through the ACE2 
receptor into type 2 pneumocytes leads to cell damage and death. Local damage may be spread by toxic effects of cytokines liberated in the inflammatory response to the virus and to these dying cells. ${ }^{19} \mathrm{~A}$ phenomenon of this sort in the brain could cause widespread dysfunction even if the infectious load is minimal.

Local infection might also damage the cells of the central nervous system by inducing changes in local biochemistry. In myalgic encephalopathy/chronic fatigue syndrome, there is evidence of brain inflammation (elevation of lactate in a variety of regions, and of choline, notably in the left anterior cingulate); this area plays an important role in cytokineinduced fatigue. ${ }^{20}$ Also in this syndrome, researchers have found elevated temperatures in 5 areas of the brain, suggesting an increase in metabolism, perhaps related to local inflammation. ${ }^{20}$ These phenomena have not been sought in COVID-19 long-hauler patients.

Brain damage due to changes in blood flow with stroke and hemorrhage was found in a review of 125 patients in the United Kingdom, as was encephalitis. ${ }^{2}$ Paterson et $\mathrm{al}^{21}$ reported similar findings. The long-term consequences of these phenomena are not yet clear.

\section{AUTOIMMUNITY, MOLECULAR MIMICRY}

Autoimmunity from SARS-CoV-2 infection is suspected to be a major force driving many of the features of COVID-19.22 A component of the virus might resemble a component of human tissue, a phenomenon known as "molecular mimicry." The immune response to the viral component then cross-reacts with the human tissue, resulting in a breakdown of tolerance, with subsequent autoimmune damage. Examples of this phenomenon with other pathogens include the following:

- Rheumatogenic Streptococcus pyogenes contains a component, $\mathrm{M}$ protein, that crossreacts with heart and brain antigens, causing pancarditis and Sydenham chorea

- Trypanosoma cruzi cross-reacts with components of human heart and nerve cells, causing chagasic myocarditis and sensory and autonomic neuropathy

- Campylobacter jejuni has been implicated in some cases of the acute motor axonal neuropathy variant of Guillain-Barré syn- drome; infection with $\mathrm{C}$ jejuni can elicit formation of antibodies to specific gangliosides, eg, GM1, GD1a, GalNac-GD1a, and GD1b, which are strongly associated with the acute motor axonal neuropathy.

The Miller-Fisher syndrome, a variant of Guillain-Barré syndrome manifesting as ataxia, areflexia, and ophthalmoplegia, has been reported following COVID-19. Immunoglobulin $\mathrm{G}$ antibodies to GD1b-IgG were detected in 1 of 2 patients with post-COVID MillerFisher syndrome reported from Spain. ${ }^{23}$ It is likely that the immunogenetic background of an individual will determine if such autoimmunity occurs.

There are many possible examples of clinically significant molecular mimicry in COVID-19. Certain peptides of SARS-CoV-2 are similar to those of alveolar surfactant protein. SARS-CoV-1 also shares 6 minimal immune determinants with the Kawasaki antigen inositol triphosphate 3 kinase $\mathrm{C},{ }^{24}$ of note because there have been reports of patients with COVID-19 developing a syndrome similar to Kawasaki syndrome. ${ }^{25-27}$ Other human proteins with sequences similar to those of SARS-CoV-2 include interleukin 7 (a deficiency of which predisposes to severe lymphopenia) and histone-lysine $\mathrm{N}$-methyl transferase $\mathrm{C}$ (linked to neurodevelopmental and behavioral abnormalities and seizures). ${ }^{24}$

Infection with SARS-CoV-2 damages cells as the virus replicates, having hijacked the cell's own mechanisms for protein synthesis. The cell ultimately ruptures, disgorging the new virus particles. During this cell lysis, cellular contents are released. In the correct immunogenetic background, these intracellular molecules, previously shielded from immune surveillance, could elicit an autoimmune response. A similar phenomenon occurs in "sympathetic ophthalmia," in which unilateral ophthalmic trauma can lead to bilateral ophthalmic inflammation. ${ }^{28}$

\section{Antibodies induce antibodies, and so on ad infinitum: The id network}

Another potential mechanism evolves from the normal method of dampening a humoral immune response. Idiotypes (ids) are the antigenic epitopes found in the antigen-binding portion of immunoglobulin molecules. The id is unique to
Local infection of the brain may occur and cause damage or dysfunction, or both 
this newly produced antibody and, as a unique and new protein, is immunogenic, eliciting an antibody response, ie, anti-id antibodies. There is, similarly, a series of anti-anti-id antibodies and anti-anti-anti-id antibodies, each with a lower peak, ultimately dampening the response as a normal regulatory mechanism.

But what if the network that emanates includes an id reactive with human tissue? When Escherichia coli dextrin was given to mice, the anti-id network that emanated included an antibody to the human acetylcholine receptor, ${ }^{29}$ an antibody linked to myasthenia gravis. In the humoral immune response to SARSCoV-2, which binds to its ACE2 receptor, an immune response to the virus might lead to an anti-anti-id antibody that might mimic the viral spike protein binding site that plugs into the ACE2 molecule, thereby producing an antibody that binds to ACE2, thereby targeting the cell and perhaps activating complement that would then damage the targeted cells. This is called the "internal image" suggested in the initial development of the id-network therapy and now being used therapeutically. ${ }^{30}$ There is as yet no evidence of this being relevant to COVID-19.

It is currently strongly suspected that COVID-19 induces autoimmunity in some patients, perhaps those with an underlying propensity for autoimmunity. There are now reports, often posted electronically before peer review, of patients having circulating antibodies to cells of the blood vessels, heart, and brain, and also autoantibodies to annexin A2, a molecule found in the small blood vessels of the lung, serving to stabilize cell membranes. ${ }^{31}$ Immune cells such as B cells can also be targeted by autoantibodies, ${ }^{32}$ as can be platelets, causing an autoimmune thrombocytopenia complicating COVID-19. ${ }^{33}$ In one study, about $10 \%$ of SARS-CoV-2-infected patients had antibodies to type 1 interferon, a molecule that usually enhances immune responses. ${ }^{34}$

\section{Antiphospholipid antibodies and thrombosis}

The thrombophlebitis that often complicates COVID-19 and can cause serious morbidity may be autoimmune as well.

Many patients produce autoantibodies to phospholipids, ${ }^{35}$ and some develop what appears to be an antiphospholipid antibody syn- drome ${ }^{36}$ long known to cause thrombophlebitis, pulmonary embolism, thrombocytopenia, recurrent pregnancy loss, various neurologic deficits, cardiac valvulitis (Libman-Sacks endocarditis), renal damage, and skin lesions, notably livedo reticularis. Such antibodies have also been found transiently after other viral infections (eg, parvovirus B19, hepatitis $\mathrm{C}$ virus, human immunodeficiency virus, varicella zoster infections), although in most postinfectious cases these antibodies do not result in thrombosis or inflammation. ${ }^{37}$ The reason for the propensity to thrombosis in COVID-19 infection is not yet clear.

In addition to autoantibodies, thrombosis may be promoted by neutrophil extracellular traps during COVID-19 infection. ${ }^{38}$

\section{CYTOKINE STORM}

Systemic (and possibly local), poorly modulated production of excess cytokines can have an adverse effect on the brain. Alpha interferon given for hepatitis $\mathrm{C}$ virus infection caused profound fatigue and often depression. Interleukin 6, a notable cytokine in severe COVID-19, is produced by lymphocytes, monocytes, fibroblasts, and bronchial epithelium. In severely ill patients, elevated interleukin 6 levels cause an increase in levels of C-reactive protein and ferritin, as well as elevations of D-dimer. The cytokine pattern seen in COVID-19 cytokine storm ${ }^{39}$ is similar to that seen in hemophagocytic lymphohistiocytosis. ${ }^{40}$ Elevated levels of interleukins $1,4,7,10,12$, and 17 , tumor necrosis factor, granulocyte colony-stimulating factor, interferon gamma-inducible protein 10 , monocyte chemoattractant protein 1 , and macrophage inflammatory protein 1 alpha have also been reported as part of this cytokine storm. ${ }^{41}$ Some of these cytokines may be produced within the central nervous system, but there is evidence that the SARS-CoV-2 spike protein can alter the blood-brain barrier.

There is evidence suggesting that interleukin 6 can regulate synaptic transmission and plasticity as well as other neuronal functions; in animal models, interleukin 6 has been found to influence cognitive function. ${ }^{42}$ High levels of interleukin 6 and of C-reactive protein have each been found to be associated 
with changes in local blood flow in the brain.

\section{COVID-19 AND BRAIN DAMAGE: SUMMING UP}

We are still early in our understanding of COVID-19 and the full spectrum of its manifestations. Mechanisms whereby it could cause brain dysfunction and damage include but are not limited to the following:

- Local infection causing cell damage caused by the virus or "innocent bystander" inflammatory damage

- Autoimmunity

- Persistence of dysfunction due to cellular disarray and faulty regeneration

- Local production of cytokines with alteration of function

- Systemic cytokine effect through a dysfunctional blood-brain barrier

- Local tissue metabolic changes due to decreased blood flow

- Altered blood flow due to thrombotic occlusion.

An appreciation of these and other underlying causes of long-hauler COVID-19 may lead to targeted therapies.

\section{PEOPLE ARE SUFFERING}

The current pandemic has been emotionally draining and very traumatic to many people. Long-term isolation, the constant worrying about interactions and masks and hand sanitizers being sufficiently protective, the fear for oneself and for one's parents and childrenall certainly contribute to a heightened level of anxiety that is immunologically and spiritually damaging. After a year on high alert, people are experiencing an unparalleled combination of combat fatigue and posttraumatic stress, and these may contribute to, but are almost certainly not the entire cause of, the persistence of symptoms.

The long-hauler phenomenon calls for an enhanced and empathetic response to the people experiencing these symptoms and to their families. Simply because there is no specific test or finding to diagnose these patients does not mean they are not suffering and certainly does not mean that their suffering is not real. No mechanisms are yet proven, but recall that in the past, miasmic air was thought to be the cause of malaria, rheumatoid arthritis was thought to be due to tuberculosis or gout, and scurvy due to "internal putrefaction" from faulty digestion related to the hardships of life at sea and the naval diet. With further research, explanations for long-hauler COVID-19 symptoms may become clearer.

\section{DISCLOSURES}

The author reports no relevant financial relationships which, in the context of his contributions, could be perceived as a potential conflict of interest.

\section{REFERENCES}

1. Marshall $\mathbf{M}$. The lasting misery of coronavirus long-haulers. Nature 2020; 585(7825):339-341. doi:10.1038/d41586-020-02598-6

2. Varatharaj A, Thomas N, Ellul MA, et al, on behalf of the CoroNerve Study Group. Neurological and neuropsychiatric complications of COVID-19 in 153 patients: a UK-wide surveillance study. Lancet Psychiatry 2020; 7(10):875-882. doi:10.1016/S2215-0366(20)30287-X

3. Wang F, Kream RM, Stefano GB. Long-term respiratory and neurological sequelae of COVID-19. Med Sci Monit 2020; 26:e928996. doi:10.12659/MSM.928996

4. Sudre CH, Murray B, Varsavsky T, et al. Attributes and predictors of long-COVID: analysis of COVID cases and their symptoms collected by the Covid Symptoms Study App. MedRxiv 19 December 2020. doi:10.1101/2020.10.19.20214494. S2CID 224805406

5. Baig AM. Deleterious outcomes in long-hauler COVID-19: the effects of SARS-CoV-2 on the CNS in chronic COVID syndrome. ACS Chem Neurosci 2020; 11(24):4017-4020. doi:10.1021/acschemneuro.0c00725

6. Honigsbaum M, Krishnan L. Taking pandemic sequelae seriously: from the Russian influenza to COVID-19 long-haulers. Lancet 2020; 396(10260):1389-1391. doi:10.1016/S0140-6736(20)32134-6

7. Kugeler KJ, Schwartz AM, Delorey M, et al. Estimating the frequency of Lyme disease diagnoses - United States, 2010-2018. Emerg
Infect Dis 2021; 27(2):616-619. doi:10.3201/eid2702.202731

8. Shorter E. From Paralysis to Fatigue: A History of Psychosomatic IIIness in the Modern Era. New York: The Free Press, 1992.

9. Li G, Fan Y, Lai Y, et al. Coronavirus infections and immune responses. J Med Virol 2020; 92(4):424-432. doi:10.1002/jmv.25685

10. Song $\mathbf{E}$, Zhang $\mathbf{C}$, Israelow $B$, et al. Neuroinvasion of SARS-CoV-2 in human and mouse brain. J Exp Med 2021; 218(3):e20202135. doi:10.1084/jem.20202135

11. Meng X, Deng Y, Dai Z, Meng Z. COVID-19 and anosmia: a review based on up-to-date knowledge. Am J Otolaryngol 2020 41(5):102581. doi:10.1016/j.amjoto.2020.102581

12. Li W, Li M, Ou G. COVID-19, cilia, and smell. FEBS J 2020; 287(17):3672-3676. doi:10.1111/ febs.15491

13. Jarvis B. What can Covid-19 teach us about the mysteries of smell? New York Times Magazine January 28, 2021. Accessed April 5, 2021. https://www.nytimes.com/2021/01/28/magazine/covid-smell-science. html

14. Buzhdygan TP, DeOre BJ, Baldwin-Leclair A, et al. The SARS-CoV-2 spike protein alters barrier function in 2D static and 3D microfluidic in-vitro models of the human blood-brain barrier. Neurobiol Dis 2020; 146:105131. doi:10.1016/j.nbd.2020.105131

15. Pezzini A, Padovani A. Lifting the mask on neurological manifestations of COVID-19. Nat Rev Neurol 2020; 16(11):636-644. doi:10.1038/s41582-020-0398-3 
16. Tsai LK, Hsieh ST, Chang Y-C. Neurological manifestations in severe acute respiratory syndrome. Acta Neurol Taiwan 2005; 14(3):113119. pmid: 16252612

17. Xu J, Zhong S, Liu J, et al. Detection of severe acute respiratory syndrome coronavirus in the brain: potential role of the chemokine MIG in pathogenesis. Clin Infect Dis 2005; 41(8):1089-1096. doi:10.1086/444461

18. Abassi Z, Knaney Y, Karram T, Heyman SN. The lung macrophage in SARS-CoV-2 infection: a friend or a foe? Front Immunol 2020; 11:1312. doi:10.3389/fimmu.2020.01312

19. Bourgonje $A R$, Abdulle $A E$, Timens $W$, et al. Angiotensin-converting enzyme 2 (ACE2), SARS-CoV-2 and the pathophysiology of coronavirus disease 2019 (COVID-19). J Pathol 2020; 251(3):228-248. doi:10.1002/path.5471

20. Mueller C, Lin JC, Sheriff S, Maudsley AA, Younger JW. Evidence of widespread metabolite abnormalities in myalgic encephalomyelitis/ chronic fatigue syndrome: assessment with whole-brain magnetic resonance spectroscopy. Brain Imaging Behav 2020; 14(2):562-572. doi:10.1007/s11682-018-0029-4

21. Paterson RW, Brown RL, Benjamin L, et al. The emerging spectrum of COVID-19 neurology: clinical, radiological and laboratory findings. Brain 2020; 143(10):3104-3120. doi:10.1093/brain/awaa240

22. Ehrenfeld M, Tincani A, Andreoli L, et al. Covid-19 and autoimmunity. Autoimmun Rev 2020; 19(8):102597. doi:10.1016/j.autrev.2020.102597

23. Gutièrrez-Ortiz C, Mèndez A, Rodrigo-Ray S, et al. Miller Fisher syndrome and polyneuritis cranialis in COVID-19. Neurology 2020; 95(5):e601-e605. doi:10.1212/WNL.0000000000009619.

24. Halpert G, Shoenfeld Y. SARS-CoV-2, the autoimmune virus. Autoimmun Rev 2020; 19(12):102695. doi:10.1016/j.autrev.2020.102695

25. Loke $\mathrm{YH}$, Berul Cl, Harahsheh AS. Multisystem inflammatory syndrome in children: is there a linkage to Kawasaki disease? Trends Cardiovasc Med 2020; 30(7):389-396. doi:10.1016/j.tcm.2020.07.004

26. Ouldali N, Pouletty M, Mariani P, et al. Emergence of Kawasaki disease related to SARS-CoV-2 infection in an epicentre of the French COVID-19 epidemic: a time-series analysis. Lancet Child Adolesc Health 2020; 4(9):662-668. doi:10.1016/s2352-4642(20)30175-9

27. Verdoni L, Mazza A, Gervasoni A, et al. An outbreak of severe Kawasaki-like disease at the Italian epicentre of the SARS-CoV-2 epidemic: an observational cohort study. Lancet 2020; 395(10239):17711778. doi:10.1016/s0140-6736(20)31103-x

28. Albert DM, Diaz-Rohena R. A historical review of sympathetic ophthalmia and its epidemiology. Surv Ophthalmol 1989; 34(1):1-14. doi:10.1016/0039-6257(89)90125-2

29. Dwyer DS, Vakil M, Kearney JF. Idiotypic network connectivity and a possible cause of myasthenia gravis. J Exp Med 1986; 164(4):1310-
1318. doi:10.1084/jem.164.4.1310

30. Lan H, Pana H, Lia R, et al. Internal image anti-idiotypic antibody: a new strategy for the development a new category of prolactin receptor (PRLR) antagonist. Mol Immunol 2017; 87:86-93. doi:10.1016/j.molimm.2017.04.006

31. Zuniga M, Gomes C, Carsons SE, et al. Autoimmunity to the lung protective phospholipid-binding protein annexin A2 predicts mortality among hospitalized COVID-19 patients. medRxiv January 4, 2021. doi:10.1101/2020.12.28.20248807 (2021).

32. Wang EY, Mao T, Klein J, et al. Diverse functional autoantibodies in patients with COVID-19. medRxiv December 12, 2020. doi:10.1101/2020.12.10.20247205

33. Bhattacharjee $\mathbf{S}$, Banerjee $\mathbf{M}$. Immune thrombocytopenia secondary to COVID-19: a systematic review. SN Compr Clin Med 2020; Sep 19:1-11. doi:10.1007/s42399-020-00521-8

34. Bastard P, Rosen LB, Zhang Q, et al. Autoantibodies against type I IFNs in patients with life-threatening COVID-19. Science 2020; 370(6515):eabd4585. doi:10.1126/science.abd4585

35. Zuo Y, Estes SK, Ali RA, et al. Prothrombotic autoantibodies in serum from patients hospitalized with COVID-19. Sci Transl Med 2020; 12(570):eabd3876. doi:10.1126/scitrans/med.abd3876

36. Cavalli E, Bramanti A, Ciurleo R, et al. Entangling COVID-19 associated thrombosis into a secondary antiphospholipid antibody syndrome: diagnostic and therapeutic perspectives. J Mol Med 2020; 46(3):903-912. doi:10.3892/ijmm.2020.4659

37. Asherson RA, Cervera R. Antiphospholipid antibodies and infections. Ann Rheum Dis 2003; 62(5):388-393. doi:10.1136/ard.62.5.388

38. Zuo Y, Zuo M, Yalavarthi S, et al. Neutrophil extracellular traps and thrombosis in COVID-19. J Thromb Thrombolysis 2020; 51(2):446453. doi:10.1007/s11239-020-02324-z

39. Jose RJ, Manuel A. COVID-19 cytokine storm: the interplay between inflammation and coagulation. Lancet Respir Med 2020; 8(6):e46e47. doi:10.1016/S2213-2600(20)30216-2

40. Ruscitti P, Berardicurti O, Di Benedetto P, et al. Severe COVID-19, another piece in the puzzle of the hyperferritinemic syndrome. An immunomodulatory perspective to alleviate the storm. Front Immunol 2020; 11:1130. doi:10.3389/ fimmu.2020.01130

41. Ye Q, Wang B, Mao J. The pathogenesis and treatment of the 'cytokine storm' in COVID-19. J Infect 2020 Jun; 80(6):607-613. doi:10.1016/j.jinf.2020.03.037

42. Gruol DL. IL-6 regulation of synaptic function in the CNS. Neuropharmacology 2015; 96(pt A):42-54. doi:10.1016/j.neuropharm.2014.10.023

Address: Leonard H. Sigal, MD, PO Box 301, Stockbridge, MA 01262; lensiga/@gmail.com 